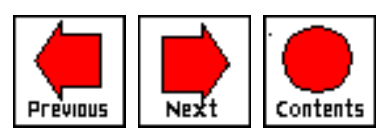

\title{
EFFECTIVENESS OF VIRTUAL REALITY IN THE MOTIVATIONAL PROCESSES OF LEARNERS
}

Sarah M. North\{\{ $\{$ bio \& photo $\}\}$ Clark Atlanta University, Atlanta GA

Editor: Karin Wiburg

\section{ABSTRACT}

This brief article reports on the use of virtual reality and its effectiveness on improving and maintaining learners' intrinsic motivation or interest. Research suggests that interest contributes to learning. Therefore a study of the impact of interests is essential to an understanding of intrinsic motivation. Since the virtual environment provides a sense of presence, it may be possible to create scenarios to stimulate the learners' curiosity and interest.

Eighteen students, 11 males and 7 females, between 21 and 32 years old, served as subjects for the study. The experiment consisted of the physical world environment using wooden blocks, and the virtual world using virtual blocks. Both worlds used color and shape as variables. The two variables consisted of three shapes (sphere, pyramid, and cube), and three colors (red, green, and blue). In both worlds, the wooden blocks and virtual blocks had to be manipulated and arranged in nine different patterns.

The first experiment started with a two-block pattern. At each step the difficulty was increased by increasing the number of blocks. The subject's score was based on a ten-point scale instrument administered at the end of each experiment. The scores ranged from very weak to very strong. The results were used to identify a significant difference between the subjects' performance in the virtual world and in physical world with respect to curiosity, interest, and sense of control.

The interest level comparison indicated that for all subjects scores in the virtual world were always higher than the scores in the physical world. The sense of control level comparison indicated that in the beginning scores in the virtual 
world were not always higher than the scores in the physical world. However, after orientation to navigation through the virtual environment, the mean score gradually rose. This research demonstrates that the virtual world is more useful than the physical world (with respect of color and shape) in increasing the memory span of the learner.

\section{Introduction}

Virtual Reality (virtual environments) offers a new human-computer interaction paradigm in which users are no longer simply external observers of data or images on a computer screen, but are active participants within a computergenerated three-dimensional virtual world. Virtual reality differs from traditional displays in that computer graphics, various displays, and input technologies are integrated to give the user a sense of presence or immersion in the virtual reality [Held \& Durlach, 1992], [Sheridan, 1992], [North \& North, 1994].

Consistent with Piagetian thinking, research suggests that learners' interactive experiences with computers provide opportunities for them to actively explore, test, create, invent new activities and observe the outcome of their efforts [Schetz, 1994], [Clements, 1991], [Haugland \& Shade, 1988]. Researchers [Shade \& Watson, 1988] postulate that when learners have meaningful interactions with discovery-oriented, open-ended software, the computer becomes an important teaching tool. Recently virtual reality application of psychological disorders has demonstrated that a person's perceptions of physical-world situations and behavior in the physical world may be modified by their experience in the virtual world. [North \& North, 1994], [North, North \& Coble, 1995].

The primary purpose of this research was to carry out a study of the effectiveness of virtual reality on improving and maintaining learners' intrinsic motivation or interest. By providing virtual environments that stimulate curiosity, interest, and a sense of control, learners can be taught to generate their own motivational strategies. Since the virtual environment provides a sense of presence and intuitive interaction techniques, it may be possible to create scenarios to stimulate the learners' curiosity and interest.

\subsection{THE SENSE OF PRESENCE}

The sense of presence that users experience in a virtual reality is perhaps the best-known attribute of virtual reality. It is an appeal to this sense of presence that is used to distinguish virtual reality as something different from a multimedia system or an interactive computer graphics display. 
A number of articles dealing with the experience of presence in a virtual or remote environment have been published recently. Sheridan [Sheridan,1992] proposed three measurable physical variables that determine presence: 1) extent of sensory information; 2) control of relation of sensors to the environment and 3) ability to modify the physical environment. Both Naiman [Naiman, 1992] and Loomis [Loomis, 1992] have argued that the normal human experience is not of the physical world but of one's perception of the physical world. Reality is what we perceive it to be. In his taxonomy of graphics simulation systems, Zeltzer [Zeltzer, 1992] identified presence with the number and fidelity of available sensory input and output channels. Heeter [Heeter, 1992ldiscusses three dimensions (personal, social and environmental) of the subjective experience of presence. Based on his analysis of international and inter-cultural encounters, Fontaine [Fontaine, 1992], identified a sense of presence with a state of consciousness in which one experiences "realness, vividness, and feeling very much alive;" "attending the immediate situation;" "a perception of thinking and acting in new and innovative ways;" and "a broad awareness of everything around." Mowafy, Russo, and Miller (1993) investigated the role of presence in training tasks involving the construction of mental models of spatial relationships. Pausch, Shackelford and Proffitt [Pausch, Shackelford and Proffitt, 1993] have demonstrated a generic search in which users perform better in an immersive environment than a stationary display window.

\subsection{MOTIVATION AND INTEREST}

A series of commission reports, including Turning Points: Preparing American Youth for the 21st Century [Carnegie Council of Adolescent Development, 1989] and A Nation at Risk [National Commission on Excellence in Education, 1983] as well as several other scholarly and professional journals, reported that the problem of American education remains the same. The primary component of the problem is the issue of motivation [Anderman, 1994]. A number of studies including one by Haladyna and Thomas [Haladyna and Thomas, 1979] have indicated that students' attitudes and degree of interest in school, as well as interest in specific academic domains (i.e., Mathematics, Science, and Art) decrease as children get older. In particular, domain-specific attitudes have the greatest decreased. The documented decrease in motivation is a basis for serious concern. [Deci and Ryan, 1991] postulate that "intrinsically motivated behaviors are those the person undertakes out of interest" (p. 241). From this perspective, interest and intrinsic motivation are virtually synonymous [Tobias, 1994].

Research suggests that interest contributes to learning. Interest creates greater comprehension, contributes to greater use of visual imagery, and stimulates a more personal, emotional, and more extensive network of relevant associations 
[Tobias, 1994]. The effects of interest on learning, retention, and cognitive processing is an important issue to study. Deci [Deci, 1992] has demonstrated that people enjoy tasks that interest them whether they lead to the attainment of rewards and other goals or not. A study of the impact of interests is essential to an understanding of intrinsic motivation. Furthermore, research has reported a greater use of visual imagery than content [Long, Winogard, and Bridge, 1989]. Furthermore, Anderson and Kulhavy [Anderson and Kulhavy, 1972] report that the use of imagery, like interest, is associated with an increase in comprehension. The stimulation of pleasant emotions increased the recall of personal experiences [Schiefele, 1992]. Several investigations report that such processes are likely to make material more vivid and distinctive and lead to more frequent and deeper cognitive processing of comprehension.

\section{Methodology}

\subsection{SUBJECTS}

Eighteen adult subjects attending the Clark Atlanta University summer session participated in this study. The subjects represented three different ethnic backgrounds (12 African Americans, four Asians, and two Africans). They ranged between 21 and 32 years old with a mean age of 26.5. 11 were males and 7 were females. The students were self-reported subjects who had not participated in any other virtual reality experiment.

\subsection{MATERIAL AND APPARATUS}

The experiment consisted of two types of environments, the physical world (using wooden blocks), and the virtual world (using virtual blocks). Both worlds used two type of variables (color and shape). The two variables consisted of three shapes (sphere, pyramid, and cube), and three colors (red, green, and blue).

The study employed objects as stimuli in both worlds. In the physical world and virtual world, the wooden blocks and virtual blocks had to be manipulated and arranged in nine different patterns. The virtual reality system for this study consisted of a personal computer with virtual reality software (VREAM Inc.), a head-mounted display (CyberEye HMD, General Reality Company), and an electromagnetic head-tracker (Flock of Birds, Ascension Inc.). Data gloves were worn to manipulate, interact with, and navigate the objects within the virtual world. \{\{photo $\}$

\subsection{EXPERIMENTERS}


The experimenters who administered all of the experiments were three undergraduate seniors and one graduate computer science major. They spent several hours learning about the physical and virtual worlds, practicing manipulation and navigation of objects and performing the tasks. They spent approximately four hours practicing and administering the experiment to each other.

\subsection{PROCEDURE}

Each subject was tested individually and a rapport was established to make the subject feel comfortable. Each subject was given a demonstration of how to handle the materials used in the physical world, and the virtual world.

Subjects were given the following instructions performing tasks in the physical world, and the virtual world:

"You have a limited time to look at each experiment."

"You have a limited time to implement each experiment."

"Look at the experiment on this card."

"You have $(30,35,40,45,50,55,60,65)$ seconds to stack your blocks like I have demonstrated in experiment $(1,2,3,4,5,6,7,8)$."

The first experiment started with two blocks pattern, the difficulty was increased by increasing the number of blocks at each step up to nine blocks. $\{$ \{Photo of screen $\}\}$ The number of blocks was increased until the subject was no longer able to reproduce them correctly (after two consecutive failures). Each experiment consisted of a block pattern which varied in shapes and colors. The shape patterns were spheres, pyramids, and cubes. The color patterns were red, green, and blue.

The following three general rating questions were asked after each session (virtual world and physical world).

What is your curiosity level?

What is your interest level?

What is your sense of control?

Each subject's score was based on the eleven-points scale instrument which was administered at the end of each experiment (very weak $=0$ to $10=$ very strong). 


\section{Results}

A paired (virtual world and physical world) ' $t$ ' test was used to identify the significance of difference between virtual world and physical world with respect to three variables (curiosity, interest, and sense of control). The curiosity level comparison between virtual world and physical world indicates that scores for all subjects $(\mathrm{N}=8$, Mean=8.10 S.D. $=.96)$ on virtual world variable were always higher than scores $(\mathrm{N}=8$, Mean=3.79, S.D.=3.27) on physical world variable $(\mathrm{t}=3.56, \mathrm{df}=14)$ respectively $\{\{$ Figure 1$\}\}$. The interest level comparison between the virtual world and the physical world indicated that for all subjects, scores $(\mathrm{N}=8, \mathrm{Mean}=7.45, \mathrm{~S} . \mathrm{D} .=1.28)$ in the virtual world were always higher than scores $(\mathrm{N}=8$, Mean $=4.75, \mathrm{~S} . \mathrm{D} .=3.97)$ in the physical world $(\mathrm{t}=1.82, \mathrm{df}=14)$ respectively \{ \{ Figure 2$\}$.

The sense of control level comparison between the virtual world and the physical world indicated that scores $(\mathrm{N}=8$, Mean=10.20, S.D. $=4.47)$ in the virtual world were not always higher than scores $(\mathrm{N}=8$, Mean=4.04, S.D. $=3.44)$ in the physical world $(\mathrm{t}=2.89, \mathrm{df}=14)$, specifically at the beginning \{ \{ Figure 3\} \}. However, after oriented to navigation through the virtual environment the mean score rose gradually.

\section{Conclusion}

The results led to the conclusion that the virtual world is more useful than the physical world (with respect of color and shape) in increasing the memory span of the learner. Based on observation, it was obvious that each subject was excited, enthusiastic, and eager to be in virtual environment, rather than the physical environment.

The main conclusions of this research are as follows:

Memory span increased significantly more in the virtual world than in the physical world.

When the subject had enough interaction "pulled into" with the virtual world, memory span increased significantly.

Consequently, it was concluded that when compared to the real world, the subject's cognitive resources increased in the virtual reality.

This research study revealed that the virtual reality technology can stimulate learners' curiosity, interest, and a sense of control.

Ultimately, the virtual reality stimulates learners' motivation, comprehension 
and interest for a longer period of time than the same experiences in the physical world.

\section{ACKNOWLEDGMENTS}

This research project was sponsored by a grant from Boeing Computer Services (Dr. David Mizell, Manger of Virtual Systems Department), partially supported by U.S. Army Center of Excellence in Information Science under contract number DAAL03-92-6-0377, and CAU/MASTER Institute program. We thank Latonya Smith and Fharon Hicks, Jamie Hamelton, and Derick Nelson for participating in this research.

\section{REFERENCES}

Anderman, E.M. and Maehr, M. L. "Motivation and Schooling in the Middle grades" Review of Education Research (1994) Vol. 64, No. 2, pp. 287-309. $\{\{$ Return $\}\}$

Anderson, R. C. and Kulhavy, R. W. "Imagery and Prose Learning" Journal of Educational Psychology (1972) Vol. 63, pp. 242-243. \{\{Return\}\}

Carnegie Council on Adolescent Development "Turning Point: Preparing American Youth for the 21st Century" (report of the Task Force on Education of Young Adolescents) (1989) New York: Author. \{ \{ Return\}\}

Deci, E. L. The Relation of Interest to the Motivation of Behavior: A Self-determination Theory Perspectives, The Role of Interest in Learning and Development Hillsdale, NJ: Erlbaum (1992) pp. 43-70. \{\{Return\}\}

Deci, E. L., and Ryan, R. M. "A. motivational approach to self: Integration in Personality, Perspectives on Motivation, Nebraska Symposium on Motivation Lincoln, NE: University of Nebraska Press (1991) pp. 237-288. \{ \{ Return\}\}

Fontaine, G. "The Experience of a Sense of Presence in Intercultural and International Encounters" PRESENCE, Teleoperators and Virtual environments (1992) Vol. 1, No. 4, pp. 482, 490. \{\{ Return\}\}

Haladyna, T. and Graham, S. "The Attitudes of Elementary School Children Toward School and Subject Matters" Journal of Experimental Education (1979) Vol. 48, pp. 18-23. \{\{ Return\}\}

Haugland, S. and Shade, D. "Developmentally Appropriate Software for Young Children" Young Children (1988) Vol. 43, pp. 37-43. \{\{ Return\}\} 
Heeter, C. "Being There: the Subjective Experience of Presence" PRESENCE, Teleoperators and Virtual Environments (1992) Vol. 1, No. 2, pp. 262-271. $\{\{$ Return $\}\}$

Held, R. M. and Durlach, N. I. "Presence" PRESENCE, Teleoperators and Virtual Environments (1992) Vol. 1, No. 1, pp. 109-112. \{\{Return\}\}

Long, S. A., Winogard, P. N., and Bridge, C. A. "The Effects of Reader and Text Characteristics on Imagery Reported During and After Reading Reading Research Quarterly (1989) Vol. 14, pp. 353-372.\{\{Return\}\}

Loomis, J. M. "Understanding Synthetic Experience Must Begin with the Analysis of Ordinary Perceptual Experience" IEEE Symposium on Research Frontiers in Virtual Reality San Jose, California (1993) pp. 54-57. \{ \{ Return\}\}

Mowafy, L. Russo, T. and Miller, L. "Is 'Presence' a training issue?" IEEE Symposium on Research Frontiers in Virtual Reality, San Jose, California (1993) pp. 124-125. \{ \{ Return\}\}

Naiman, A. Presence, and Other Gifts" PRESENCE, Teleoperators and Virtual environments (1992), Vol. 1, No. 1, pp. 145-148. \{\{ Return\}\}

National Commission on Excellence in Education, A Nation at Risk (1993) Washington, DC: Author. \{ \{ Return\}\}

North, M. M. and North, S. M. "Relative Effectiveness of Virtual Environment Desensitization and Imaginal Desensitization in the Treatment of Acrophobia" Electronic Journal of Virtual Culture, ISSN 1068-5723 (1994) Vol. 2, No. 4, pp. 37-42. \{ \{ Return\}\}

North, M. M. and North, S. M. "Relative Effectiveness of Virtual Environment Desensitization and Imaginal Desensitization in the Treatment of Acrophobia" Electronic Journal of Virtual Culture, ISSN 1068-5723 (1994) Vol. 2, No. 4, pp. 37-42. \{\{ Return\}\}

North, M. M., North, S. M., and Coble, J. R. "An Effective Treatment for Psychological Disorders: Treating agrophobia with Virtual Environment Desensitization" CyberEdge Journal (1995) No. 5, No. 3, pp. 12-13. \{\{Return\}\}

Pausch, R., Shackelford, M. A. and Proffitt, D. "A User Study Comparing Head-Mounted and Stationary Displays" IEEE Symposium on Research Frontiers in Virtual Reality San Jose, California, (1993), pp. 41-45. \{\{Return\}\}

Saks, J. The Effects of Topic Interest and Prior Knowledge on Readers' Cognitive Processing of Text, Unpublished doctoral dissertation, City University of New York (1988). \{ \{ Return\} \} 
Schetz, K. F. "Teacher-Assisted Computer Implementation: A Vygotskian Perspective" Early Education and Review (1994) No. 5, No. 1, pp. 18-26. $\{\{$ Return $\}\}$

Schiefele, U. "Interest, Learning and Motivation" Educational Psychologist (1991) No. 26, pp. 299-323. \{ \{Return\}\}

Sheridan, T, B. "Musing on Teleoperations and Virtual Presence" PRESENCE, Teleoperators and Virtual Environments (1992) No. 1, No. 1, pp. 120-126. $\{\{$ Return $\}\}$

Sheridan, T, B. "Musing on Teleoperations and Virtual Presence" PRESENCE, Teleoperators and Virtual Environments (1992) No. 1, No. 1, pp. 120-126. $\{$ Return\}\}

Tobias, S. "Interest, Prior Knowledge, and Learning" Review of Educational Research (1994), Vol. 64, No. 1, pp. 37-54. \{\{Return\}\}

Tobias, S. "Interest, Prior Knowledge, and Learning" Review of Educational Research (1994), Vol. 64, No. 1, pp. 37-54. \{\{Return\}\}

Zeltzer, D. "Autonomy, Interaction and Presence" PRESENCE, Teleoperators and Virtual Environments (1992), Vol. 1, No. 1, pp. 127-132. \{\{Return\}\}

\section{BIOGRAPHY}

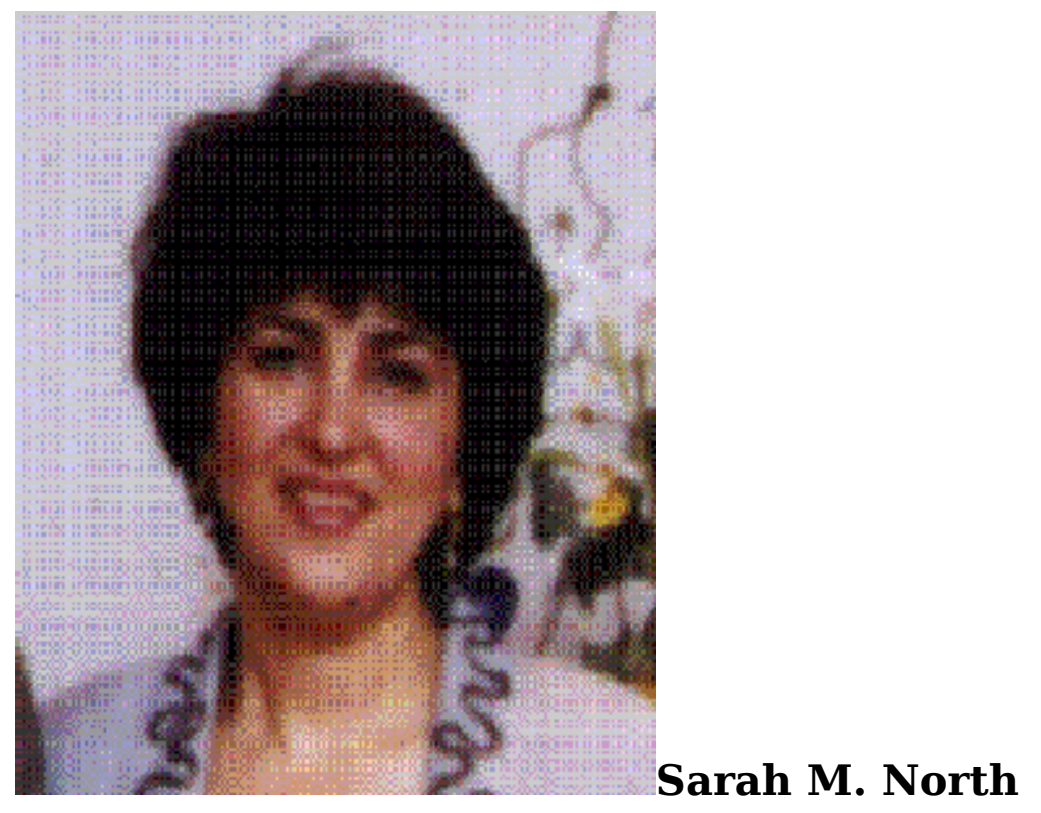

SARAH M. NORTH obtained her M.S. in Computer Science from Atlanta University, and she expects to receive her Ph.D. in Counseling and Human 
Development (Cognitive Science) from Clark Atlanta University in 1996. She is Assistant Professor of Computer and Information Science and Co-director of Human-Computer Interaction Group and Virtual Display Systems Laboratory. She is the author of several articles in the field of computing and psychology.

Professor North's field of research is cognitive science and human-computer interaction. She focuses on the effectiveness of virtual environments in the motivational processes of learners.

Professor North's current projects include i) the study of effectiveness of virtual environments for improving and maintaining intrinsic motivation of learners, and ii) the development of better information visualization tools to support the characteristic of the human cognitive process.

Contact Information: Sarah M. North

Computer and Information Science Department

Clark Atlanta University

Atlanta, Georgia, 30314

Phone: 404-880-6957

Fax: 404-880-6963

Email: sarah@acm.org

Return to IJVR's Home Page

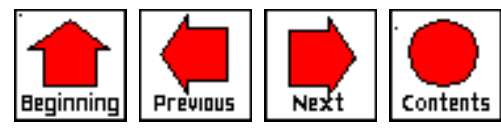



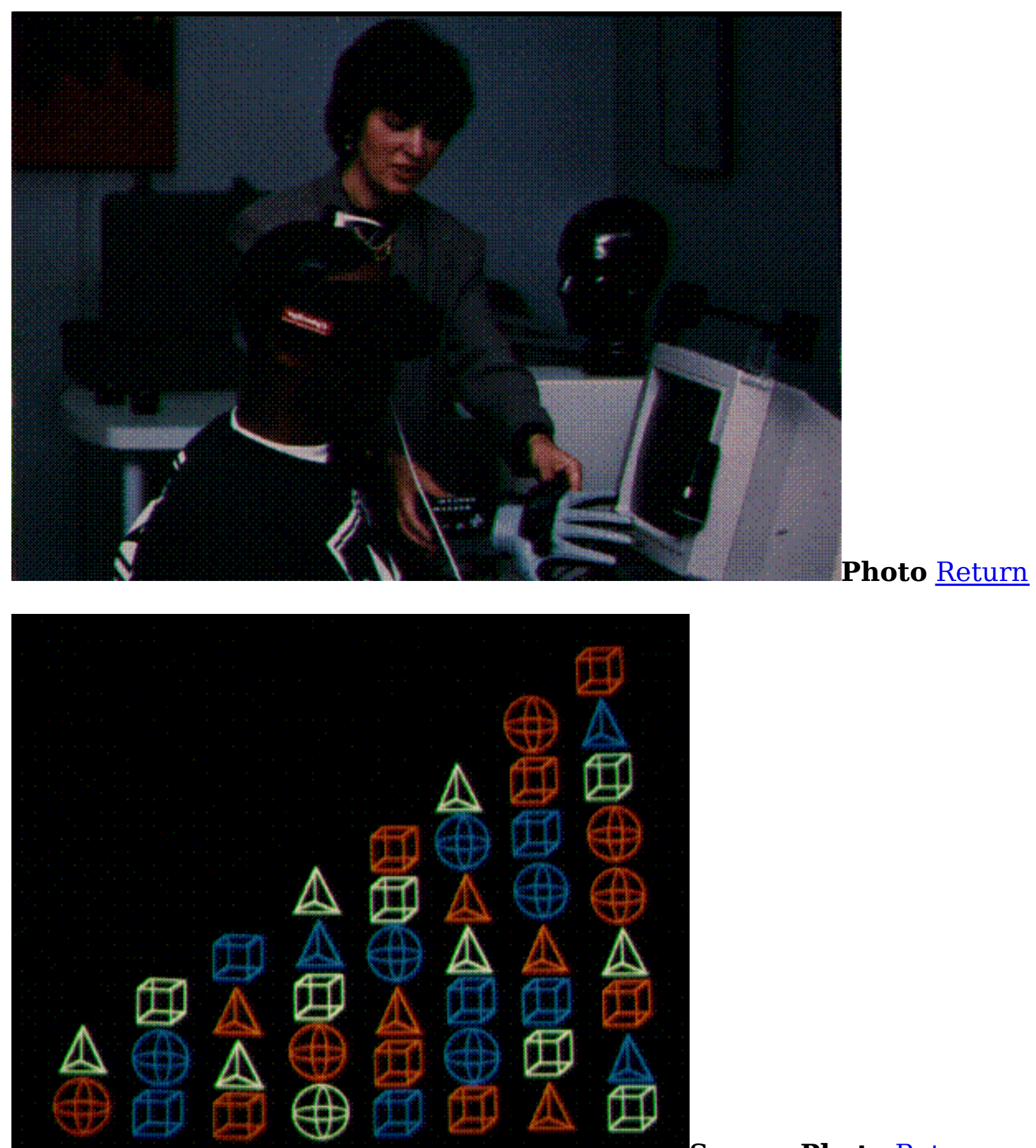

Screen Photo Return 


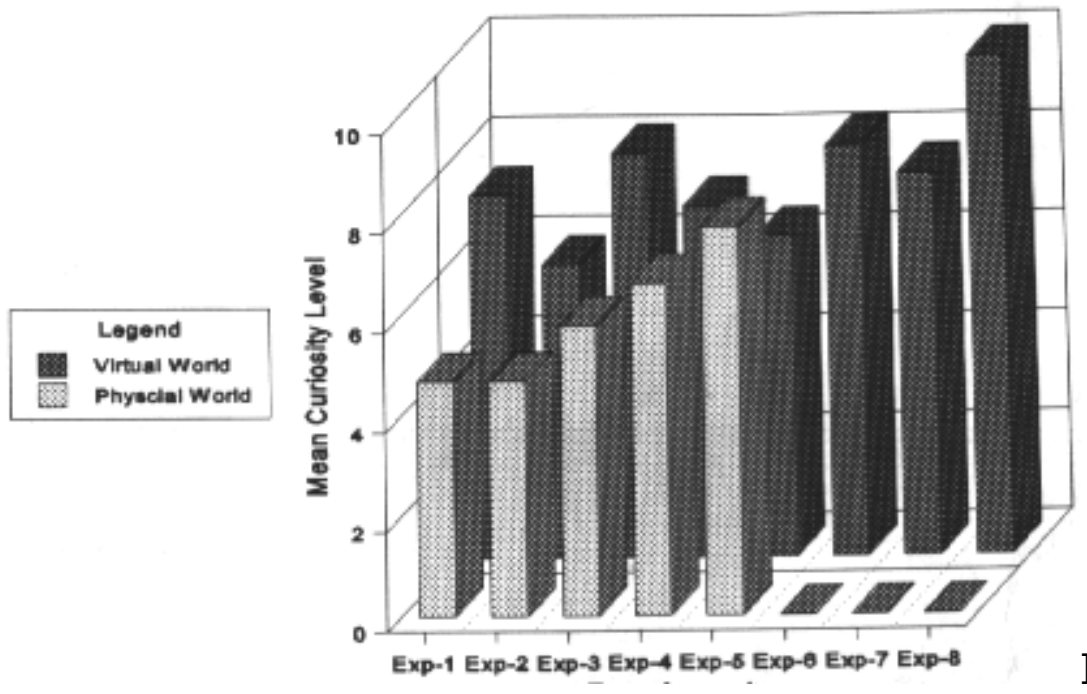

Figure $1 \underline{\text { Return }}$

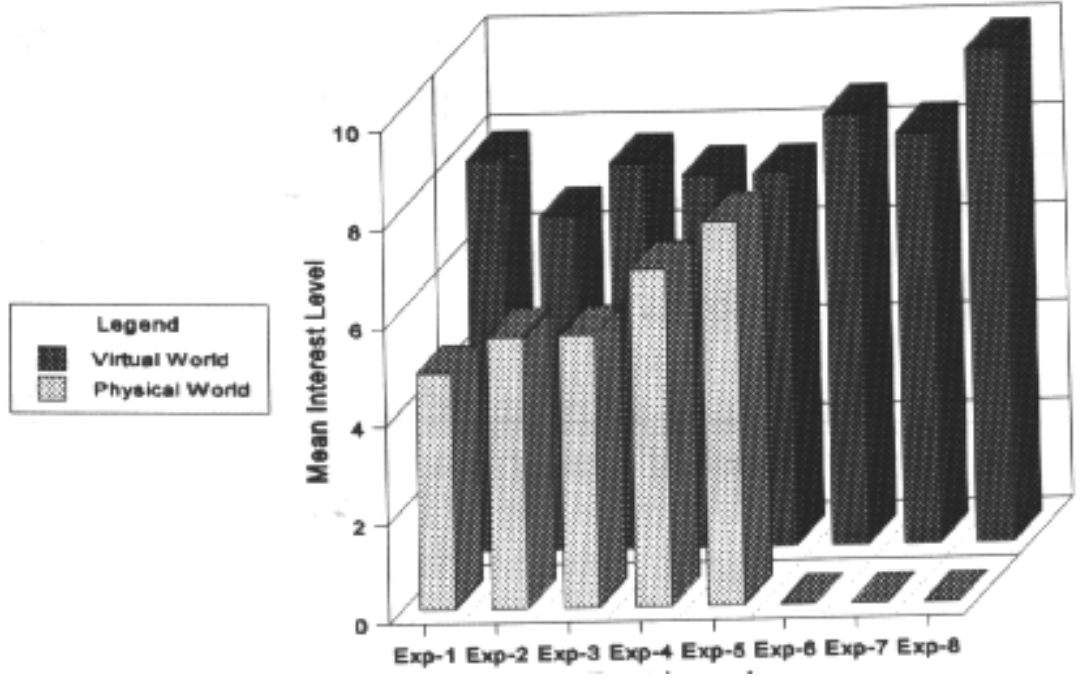

Figure 2 Return

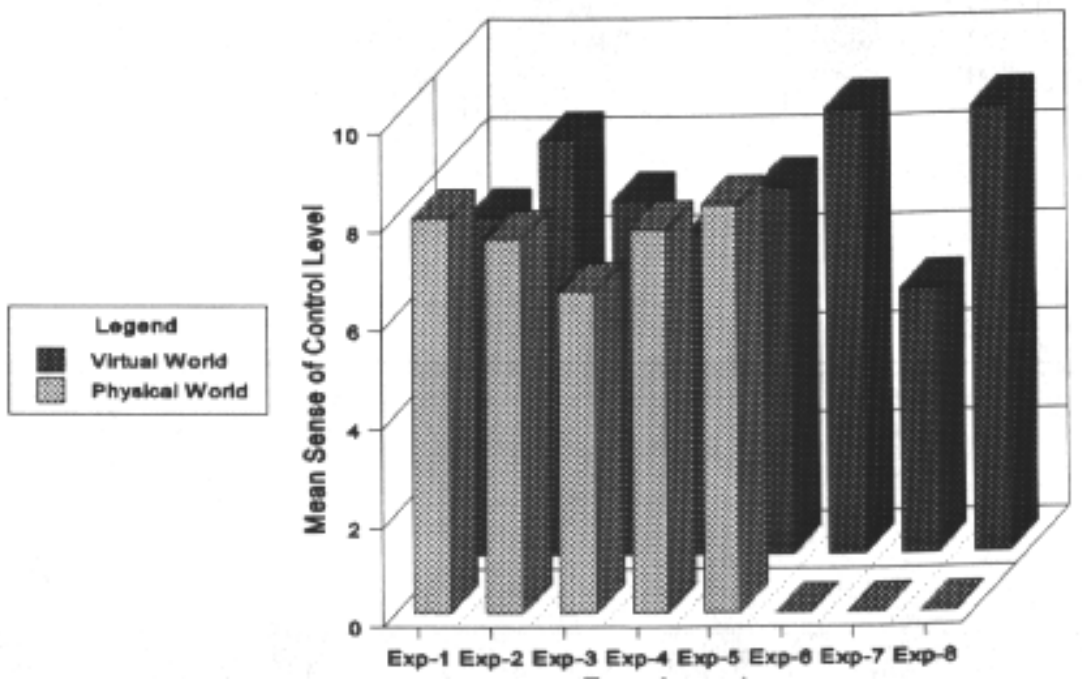

Figure $3 \underline{\text { Return }}$ 


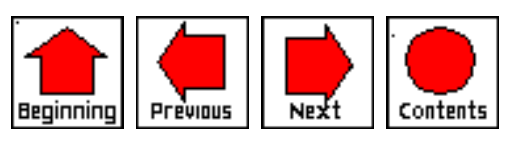

